\title{
Fur and iron transport proteins in the Brazilian purpuric fever clone of Haemophilus influenzae biogroup aegyptius
}

\author{
L. M. SMOOT, E. C. BELL, J. H. CROSA* and L. A. ACTIS \\ Department of Microbiology, Miami University, Oxford, OH 45056 and *Department of Molecular Biology and \\ Immunology, Oregon Health Sciences University, Portland, OR 97201, USA
}

\begin{abstract}
The Brazilian purpuric fever (BPF) clone of Haemophilus influenzae biogroup aegyptius causes a fatal septicaemic disease, resembling fulminant meningococcal sepsis, in children. When isolate F3031 was grown under iron-limiting conditions, the presence of several iron-regulated proteins of $38-110 \mathrm{kDa}$ was revealed by electrophoretic analysis and a Fur homologue was shown by immunoblotting. Dot-blot assays and immunoblotting indicated that BPF cells bound human transferrin and contained transferrinbinding proteins in the outer membrane. However, the binding activity and the biosynthesis of these proteins were detected even under iron-rich conditions. Immunoblot analysis demonstrated the presence of a periplasmic protein related to the ferric ironbinding protein A (FbpA), the major iron-binding protein described in Neisseria spp. However, the FbpA homologue in strain F3031 was constitutively expressed and was smaller than the periplasmic protein detected in $H$. influenzae type b strain Eagan. The periplasm of strain F3031 also contained a protein related to the Streptococcus parasanguis FimA protein which recently has been shown to be involved in iron acquisition in Yersinia pestis. Although the Eagan and F3031 FimA homologues had a similar mol. wt, of $31 \mathrm{kDa}$, the expression of the BPF fimA-like gene was not regulated by the iron concentration of the culture medium.
\end{abstract}

\section{Introduction}

Brazilian purpuric fever (BPF) is a fatal invasive disease in children that initially manifests as a purulent conjunctivitis [1-3]. Typically, 1-2 weeks after the conjunctivitis resolves, BPF patients experience acute onset of fever associated with abdominal pain and vomiting. These patients usually die within $48 \mathrm{~h}$ due to disseminated purpura, vascular collapse and hypotensive shock. Haemophilus influenzae biogroup aegyptius was the only bacterium isolated from most BPF patients, indicating that it is the causative agent [4]. Epidemiological, genetic and biochemical studies demonstrated that BPF isolates form a unique clone that is more related to $H$. influenzae serotype c strains than to the classical non-invasive isolates of $H$. influenzae biogroup aegyptius that cause sporadic or epidemic conjunctivitis [4,5]. Population genetic analysis [5] supported this evidence and confirmed that, although

Received 16 July 1998; revised version accepted 4 Nov. 1998.

Corresponding author: Dr L. A. Actis.

(e-mail: actisla@muohio.edu). similar to most $H$. influenzae, biogroup aegyptius strains are genetically diverse. The BPF isolates represent a distinct genotype, based on multilocus enzyme analysis, and no other isolates related to the BPF lineage could be identified among non-typable $H$. influenzae isolates from invasive infections. Musser and Selander [5] suggested that the extensive genetic diversity of biogroup aegyptius could be due to the fact that the BPF isolates either originated from nonpathogenic clones or were transmitted from a nonhuman host, or both. The acquisition or loss of genetic material during these processes may have created the BPF form of biogroup aegyptius that expresses a new set of virulence factors unique to this $H$. influenzae clone.

Despite the numerous reports describing the biochemical [4] and the surface and adherence properties [6] of BPF and the development of an infant rat [7] and a tissue culture model [8], little is known about the bacterial factors that influence the interaction of this pathogen with the human host and the subsequent onset and dissemination of this fatal infection in children. In this study, the ability of strain F3031, the 
BPF prototype strain, to grow in iron-deficient conditions and express iron-regulated proteins was examined. The interaction of this strain with human transferrin and the expression of cell envelope proteins known to be involved in iron acquisition via siderophore-independent systems in other gram-negative bacteria were also studied.

\section{Materials and methods}

\section{Bacterial strains and culture conditions}

Strain F3031, isolated from a Brazilian child with BPF, was provided by Dr D. J. Brenner (Centers for Disease Control, Atlanta, GA, USA). $H$. influenzae type b strain Eagan was obtained from Dr S. H. Goodgal (University of Pennsylvania, Philadelphia, PA, USA). $H$. influenzae strains were grown routinely on enriched chocolate agar plates at $37^{\circ} \mathrm{C}$ in an atmosphere of $\mathrm{CO}_{2}$ $5 \%$, air $95 \%$. Liquid cultures inoculated with cells harvested from fresh, enriched chocolate agar plates were grown in brain heart infusion (BHI) broth supplemented with haemin $2 \mu \mathrm{g} / \mathrm{ml}$ and $\beta$-NAD $2 \mu \mathrm{g} / \mathrm{ml}$ (sBHI). Iron-limiting conditions were obtained by addition of the iron chelator ethylene-di-( $o$-hydroxyphenyl) acetic acid (EDDHA) at a final concentration of $100 \mu \mathrm{M}$. Iron-rich conditions were obtained by the addition of $50 \mu \mathrm{M} \mathrm{FeCl} 3$ or haemin $20 \mu \mathrm{g} / \mathrm{ml}$. Utilisation of iron and protoporphyrin IX (PPIX) was assessed with $\mathrm{BHI}$ agar plates containing $\beta$-NAD $10 \mu \mathrm{g} / \mathrm{ml}$ and PPIX $10 \mu \mathrm{g} / \mathrm{ml}$.

\section{Transferrin-binding assays}

Binding of human transferrin was evaluated with the dot-blot assay and serial two-fold dilutions of whole cells as described previously [9]. Cells were resuspended in Tris-buffered saline solution (TBS) $(50 \mathrm{mM}$ Tris-HCI, $0.15 \mathrm{M} \mathrm{NaCl}, \mathrm{pH} 7.5$ ) to an $\mathrm{A}_{600}$ of 10 , and $20-\mu \mathrm{l}$ samples were spotted on to a nitrocellulose membrane. Blots were blocked with skim milk $1 \%$ and subsequently incubated with horseradish peroxidaseconjugated human transferrin (HRP-TF; Pierce, Rockford, IL, USA) $50 \mathrm{ng} / \mathrm{ml}$ at $37^{\circ} \mathrm{C}$ for $60 \mathrm{~min}$. Membranes were developed with 4-chloro-1-naphthol and $\mathrm{H}_{2} \mathrm{O}_{2}$.

\section{Isolation and electrophoretic analysis of whole- cell lysate, membrane and periplasmic proteins}

Whole-cell lysates were prepared by solubilising equal amounts of bacterial cells with SDS-PAGE sample buffer [10] at $100^{\circ} \mathrm{C}$ for $10 \mathrm{~min}$. Total membranes were isolated by centrifugation at $40000 \mathrm{~g}$ after ultrasonic cell disruption. Outer membranes were isolated by selective solubilisation with N-lauroylsarcosine (Sarkosyl) $1.5 \%$ and centrifugation as described previously [10]. Periplasmic proteins were isolated by osmotic shock as described by Harkness et al. [11]. As a control, the activity of acid phosphatase, a periplasmic enzyme marker [12], was determined with $p$-nitrophenol phosphate (Sigma) as chromogenic substrate. Proteins were analysed by SDS-PAGE with polyacrylamide $12.5 \%$ gels as described previously [10]. Protein concentrations were determined by the method of Bradford [13]. Samples containing either $25 \mu \mathrm{g}$ or $50 \mu \mathrm{g}$ of proteins were loaded on to small $(8 \times 7 \mathrm{~cm})$ and large $(15 \times 15 \mathrm{~cm})$ polyacrylamide gels, respectively.

\section{Immunoblot analysis}

Proteins resolved by SDS-PAGE were transferred electrophoretically to nitrocellulose as described by Towbin et al. [14]. Membranes were blocked by incubation at $37^{\circ} \mathrm{C}$ for $30 \mathrm{~min}$ in skim milk $5 \%$ and subsequently incubated with rabbit or guinea-pig antisera. Immunocomplexes were detected with either HRP-labelled protein A or a 1 in 10000 dilution of goat anti-guinea-pig IgG conjugated to HRP (Sigma). The blots were visualised by chemiluminescence with SuperSignal CL-HRP substrate (Pierce). Rabbit polyclonal serum against the $N$. gonorrhoeae FbpA protein was obtained from Dr S. Morse (Centers for Disease Control, Atlanta) and used at a dilution of 1 in 1000 . Guinea-pig antisera against $H$. influenzae strain Eagan recombinant $\mathrm{TbpA}(\mathrm{rTbpA})$ and $\mathrm{TbpB}(\mathrm{rTbpB})$ were obtained from Dr S. M. Loosmore (Connaught Centre for Biotechnology, Ontario, Canada) and used at a dilution of 1 in 2500. Rabbit serum against purified Escherichia coli Fur protein was obtained as described previously [15] and diluted 1 in 1000 before incubation with the nitrocellulose blots. Serum against FimA was raised in a rabbit as described previously [15]. The antigen used to generate this antiserum was the $H$. influenzae Eagan FimA homologue, which was purified by SDS-PAGE and elution with an IBI Unidirectional Electro-eluter (Kodak, Rochester, NY, USA), after staining with Fast Stain (Zoion Newton, MA, USA). A 1 in 4000 dilution of this antiserum was used in the immunoblot experiments.

\section{Results \\ Iron uptake and iron regulation of gene expression in strain F3031}

Growth in iron-restricted conditions and on haemin and PPIX. The ability of this BPF isolate to grow in iron-deficient conditions was examined in sBHI containing increasing amounts of EDDHA. Liquid cultures of strain F3031 in sBHI containing up to $100 \mu \mathrm{M}$ EDDHA reached cell densities similar to the irondeficient cultures of strain Eagan, a well characterised type $\mathrm{b}$ clinical isolate that is able to grow under iron limitation [16]. As $\mathrm{F} 3031$ is a non-typable $H$. influenzae strain, its ability to acquire iron from the medium when PPIX was substituted for haemin was also assessed. This strain was able to grow readily on BHI-NAD agar plates containing free iron and PPIX $10 \mu \mathrm{g} / \mathrm{ml}$ in place of haemin. 
Identification of iron-regulated membrane proteins. The effect of iron on gene expression in strain F3031 was examined by comparing the electrophoretic profiles of membrane proteins from iron-replete and ironstarved cells. Fig. 1 shows that the total membrane fraction of this strain contained several iron-repressed proteins (compare lanes 1 and 2). Further analysis of membrane preparations treated with Sarkosyl showed that most of these proteins were located in the outer membrane and they ranged from 38 to $c .110 \mathrm{kDa}$ (Fig. 1 , lanes 3 and 4). The iron concentration of the culture medium affected the expression of membrane proteins and demonstrated that the culture conditions were appropriate for the study of iron regulation of gene expression in this bacterium, as they produced physiological changes caused by iron limitation.

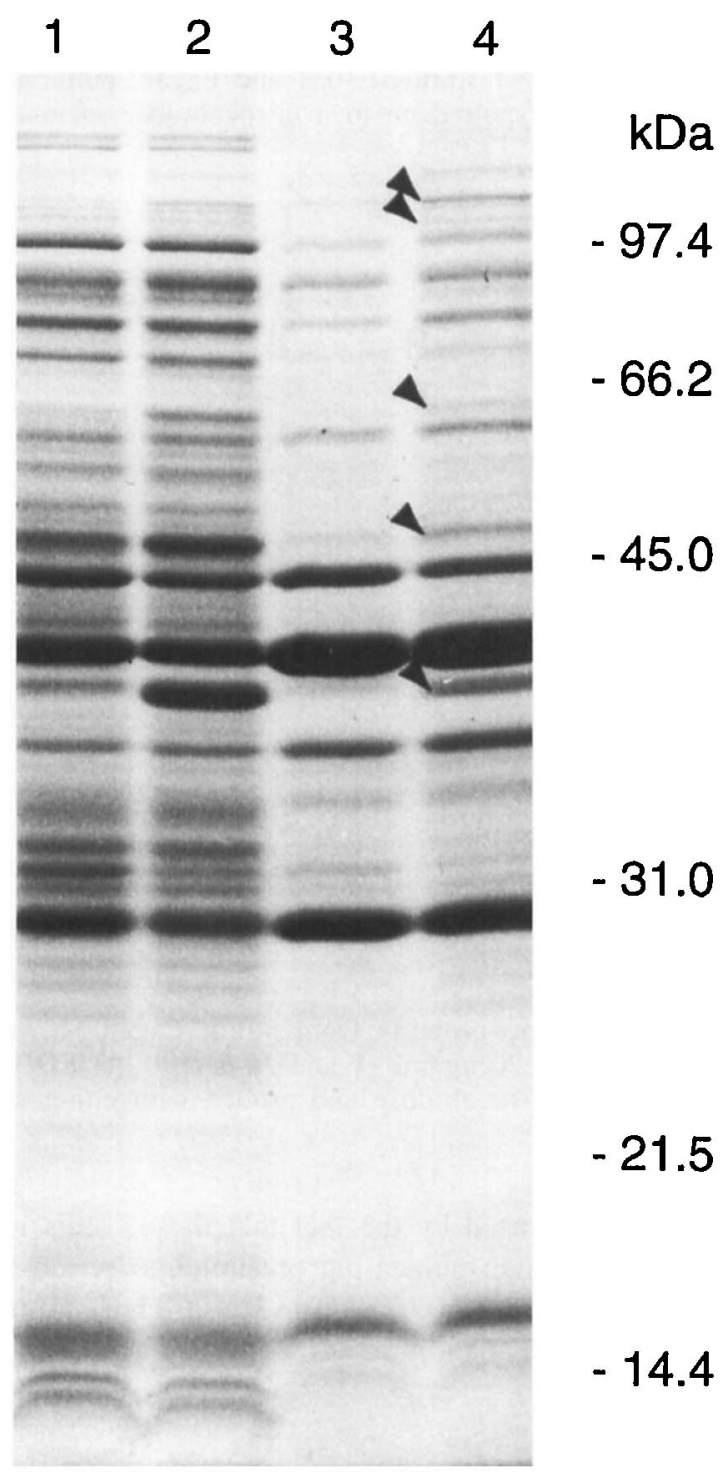

Fig. 1. Electrophoretic analysis of membrane proteins of strain F3031. Total membranes (lanes 1 and 2) and outer membranes ( 3 and 4 ) were isolated from cells grown in sBHI containing either haemin $20 \mu \mathrm{g} / \mathrm{ml}$ (1 and 3 ) or $100 \mu \mathrm{M}$ EDDHA (2 and 4). All lanes were loaded with $50 \mu \mathrm{g}$ of proteins. The arrowheads identify iron-repressed outer-membrane proteins. Mol. wt markers are indicated on the right.
Identification of Fur. The results in Fig. 1 indicated that the genome of strain F3031 contains iron-regulated genes. The expression of iron-regulated genes in gramnegative bacteria is controlled mainly by a repressor protein named Fur [17]. Immunoblotting with an antiserum aganist the purified Fur protein of $E$. coli [15] revealed a single polypeptide band, which co-migrated with the $17-\mathrm{kDa}$ Fur protein of $E$. coli in whole-cell lysates of cells grown in either excess haemin or EDDHA (Fig. 2). Thus, strain F3031 appears to express a Fur homologue.

\section{Analysis of cell envelope proteins involved in iron} acquisition

Detection of transferrin-binding activity and transferrin-binding proteins. Dot-blot assays with serial dilutions of whole-cell suspensions showed that strain F3031 bound human transferrin (Fig. 3). Transferrinbinding activity was detectable even in cells cultured in sBHI supplemented with haemin $20 \mu \mathrm{g} / \mathrm{ml}$ (iron-rich conditions) and then diluted to an $\mathrm{OD}_{600}$ of 1.2. Similar results were obtained when the sBHI medium was supplemented with $50 \mu \mathrm{M} \mathrm{FeCl}{ }_{3}$ (data not shown). Conversely, $H$. influenzae strain Eagan bound transferrin when grown in sBHI containing EDDHA, whereas binding was barely detectable when cells were cultured in sBHI supplemented with haemin $20 \mu \mathrm{g} / \mathrm{ml}$ and then adjusted to an $\mathrm{OD}_{600}$ of $c .10$.

The expression of transferrin-binding proteins by strain F3031 was examined by immunoblotting with guinea-pig anti-rTbpA and anti-rTbpB sera [18]. As shown by Loosmore et al. [18], the anti-rTbpA (Fig. $4 \mathrm{a}$, lanes 1 and 2) and anti-rTbpB (Fig. 4b, lanes 1 and 2) sera recognised specific protein bands located in the outer membrane of strain Eagan. Fig. 4b also shows that the biosynthesis of these proteins was ironregulated, although the expression of $\mathrm{TbpB}$ was more sensitive than that of TbpA to the iron concentration

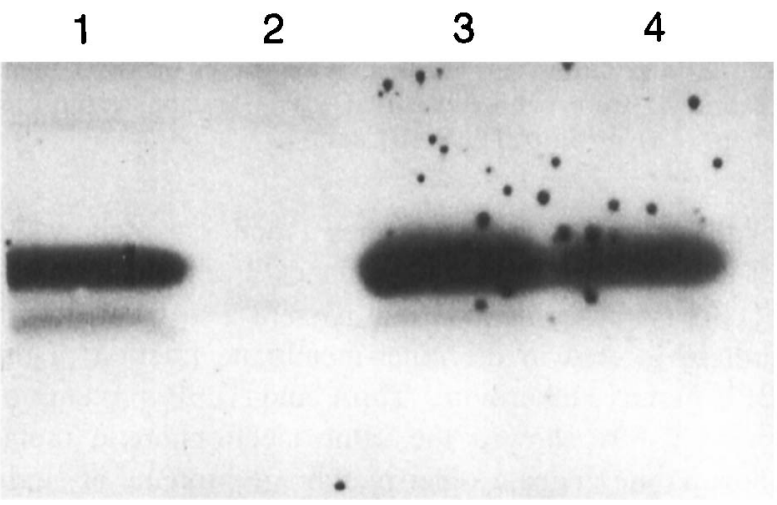

Fig. 2. Immunoblot analysis of Fur. Whole-cell lysates of $E$. coli $\mathrm{BN} 402\left(\mathrm{Fur}^{+}\right)$(lane 1), E. coli BN4020 (Fur $\left.{ }^{-}\right)$ (2) and $H$. influenzae biogroup aegyptius strain F3031 grown in sBHI containing either haemin $20 \mu \mathrm{g} / \mathrm{ml}(3)$ or $100 \mu \mathrm{M}$ EDDHA (4) were subjected to SDS-PAGE, transferred electrophoretically to nitrocellulose and probed with anti-Fur serum. 


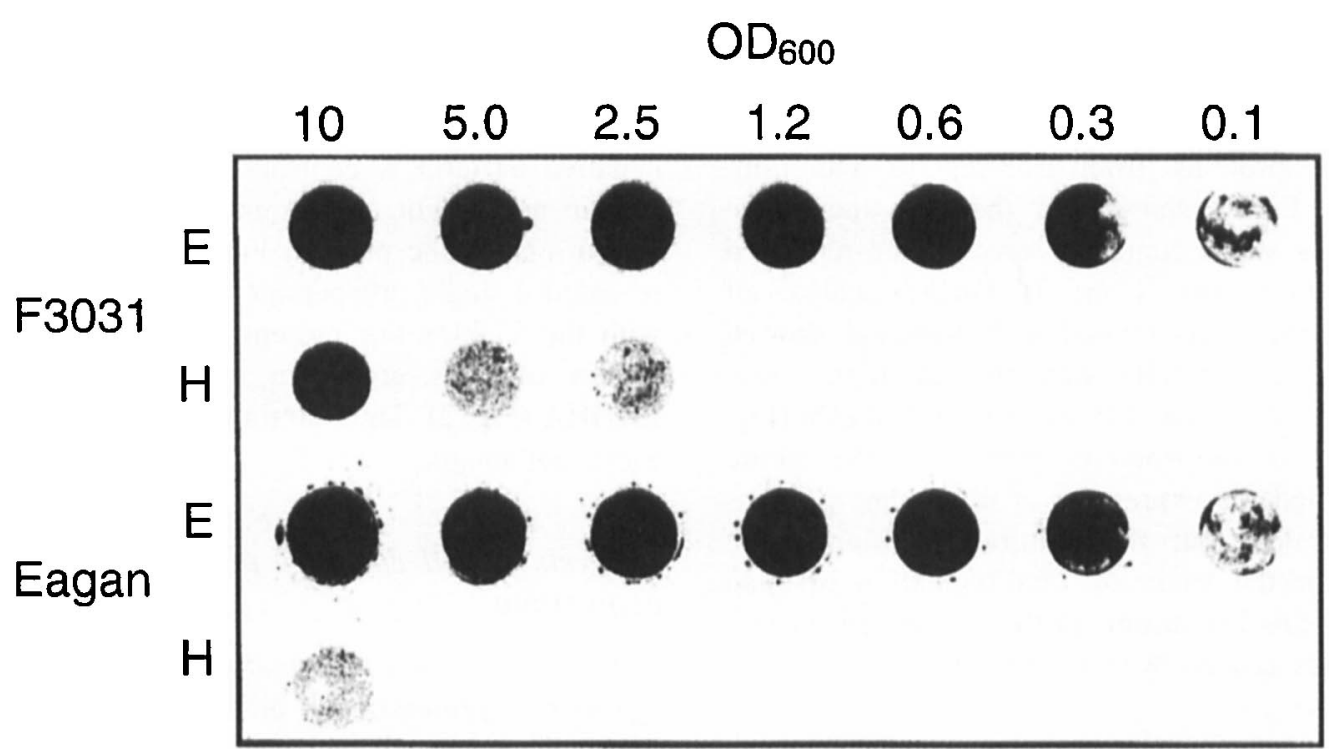

Fig. 3. Binding of human transferrin. Serially diluted whole-cell suspensions of strains F3031 and Eagan, cultured in sBHI containing either $100 \mu \mathrm{M}$ EDDHA (E) or haemin $20 \mu \mathrm{g} / \mathrm{ml}(\mathrm{H})$, were spotted on to a nitrocellulose membrane before incubation with HRP-TF.

\section{a}

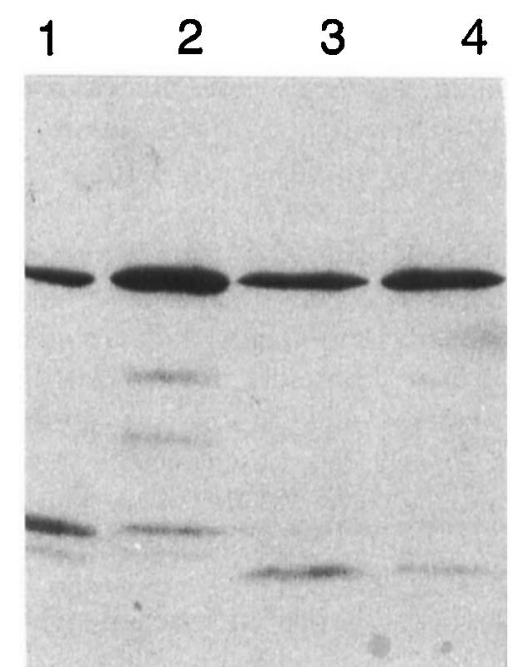

b

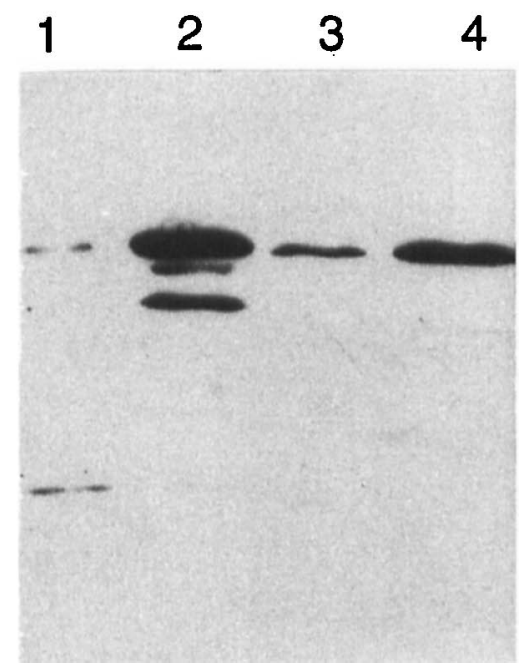

Fig. 4. Immunoblot analysis of transferrin-binding proteins. Outer-membrane proteins from strain Eagan (lanes 1 and 2) and strain F3031 (3 and 4) grown in sBHI containing either haemin $20 \mu \mathrm{g} / \mathrm{ml}$ (1 and 3) or $100 \mu \mathrm{M}$ EDDHA ( 2 and 4) were subjected to SDS-PAGE, transferred electrophoretically to nitrocellulose and probed with either antirTbpA (a) or anti-rTbpB (b) sera.

of the medium (compare lanes 1 and 2, panels a and b). The anti-rTbpA (Fig. 4a, lanes 3 and 4) and antirTbpB (Fig. 4b, lanes 3 and 4) sera also reacted with protein located in the outer-membrane fraction of the $\mathrm{BPF}$ clone. Futhermore, TbpA and $\mathrm{TbpB}$ proteins of strain F3031 showed the same electrophoretic mobilities as the cognate outer-membrane proteins of strain Eagan. In the BPF isolate, expression of the gene encoding $\mathrm{TbpB}$ was more responsive to the iron concentration of the culture than the expression of the gene encoding TbpA (Fig. 4, compare lanes 3 and 4, panels $a$ and $b$ ). The smaller protein bands detected with these antisera may represent degradation products of the TbpA and TbpB native proteins. This pos- sibility is supported by the fact that these bands were not detected when guinea-pig pre-immune serum was used (data not shown). The TbpA and TbpB proteins of strain F3031 had mol.wts of c. 90 and $80 \mathrm{kDa}$, respectively.

Detection of the HitA iron-binding protein. The presence of periplasmic iron-binding proteins in the BPF clone, such as the highly homologous FbpA and HitA proteins required for iron uptake in neisseriae [19-21] and non-typable $H$. influenzae strains [22], respectively, was examined by SDS-PAGE and immunoblotting. Fig. 5a shows that strain Eagan contained a major $40-\mathrm{kDa}$ iron-regulated protein that was present in whole-cell 
a
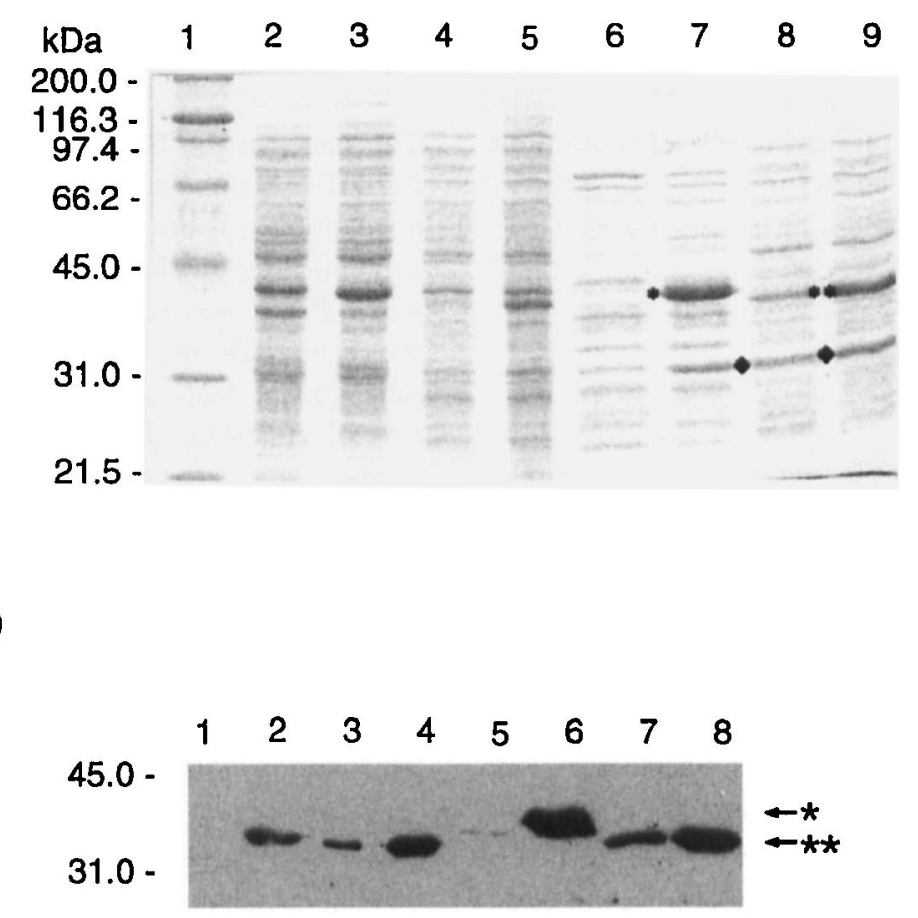

C

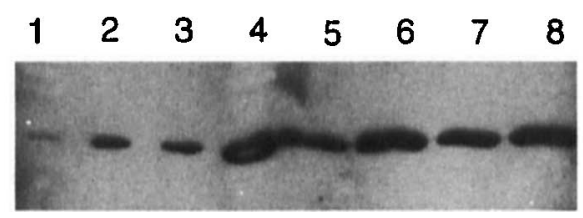

Fig. 5. Electrophoretic and immunoblot analysis of whole-cell extracts and periplasmic proteins (a) SDS-PAGE of whole-cell lysates (lanes 2-5) and osmotic-shock fluids (6-9), obtained from strain Eagan $(2,3,6$ and 7$)$ and strain F3031 (4, 5,8 and 9) cultured in sBHI containing either haemin $20 \mu \mathrm{g} / \mathrm{ml}(2,4,6$ and 8) or $100 \mu \mathrm{M}$ EDDHA (3,5,7 and 9). Lane 1, mol.wt markers. Single and double asterisks indicate the position of the 40- and 38-kDa proteins related to FbpA, respectively. Diamonds indicate the position of the $31-\mathrm{kDa}$ protein related to FimA. (b) Immunoblot analysis of HitA. Whole-cell lysate (lanes 1-4) and osmotic-shock fluids (5-8), obtained from strain Eagan (1, 2, 5 and 6) and strain F3031 (3, 4,7 and 8) cultured in sBHI containing either haemin $20 \mu \mathrm{g} / \mathrm{ml}(\mathbf{1}, 3,5$ and 7$)$ or $100 \mu \mathrm{M}$ EDDHA $(2,4,6$, and 8), were subjected to SDS-PAGE, transferred electrophoretically to nitrocellulose and probed with anti-FbpA. Single and double asterisks on the right indicate the position of the $40-$ and $38-\mathrm{kDa}$ proteins related to FbpA, respectively. Mol. wt markers are indicated on the left. (c) Immunoblot analysis of FimA; a blot identical to that shown in (b) was probed with anti-FimA.

lysates and in the periplasmic fraction of cells grown under iron limitation (compare lanes 2, 3,6 and 7). Its location within the periplasmic space was confirmed when the enzymic activity of the periplasmic enzyme marker acid phosphatase was 10 -fold greater in the periplasmic fraction than in the cytoplasmic fraction. Therefore, the mol.wt, cellular location and iron regulation suggested that this protein was the FbpA homologue. These findings were further supported by immunoblot analyses with anti-FbpA and cell fractions of strain Eagan that were obtained from iron-limited and iron-replete cultures (Fig. 5b, lanes 1, 2, 5 and 6). The results are in agreement with the first report [11] that $H$. influenzae expresses a $40-\mathrm{kDa}$ periplasmic protein that shares homology with FbpA. Although the cell extract and periplasmic samples of strain F3031 did not display a $40-\mathrm{kDa}$ protein, a significant polypeptide of $38 \mathrm{kDa}$ was detected in iron-starved as well as in iron-replete cells (Fig. 5a, lanes 4, 5,8 and 9). This protein band reacted with the FbpA antiserum, but showed less stringent iron regulation than in strain Eagan (Fig. 5a, lanes 2, 3,6 and 7).

Detection of the FimA homologue. It was shown previously that the periplasmic fraction of strain Eagan contained a $31-\mathrm{kDa}$ iron-regulated protein [11]. Based on sequence data, this protein is homologous to $\mathrm{ABC}$ transporter components involved in iron uptake $[23,24]$. Thus, the expression of this putative irontransport protein in the BPF clone was examined. SDS- 
PAGE analysis demonstrated the presence of a $31-\mathrm{kDa}$ protein in the periplasm of strains Eagan and F3031. However, while expression of the protein was well regulated by iron in strain Eagan, it was almost constitutively expressed in strain F3031 (Fig. 5a, lanes 6-9). These results were confirmed by immunoblotting with the FimA polyclonal antiserum (Fig. 5c, compare lanes 1,2,5 and 6 for strain Eagan and lanes 3, 4, 7 and 8 for strain F3031).

\section{Discussion}

$H$. influenzae biogroup aegyptius requires haemin to grow under aerobic conditions due to the inability to convert $\delta$-aminolevulinic acid to protoporphyrin IX [25]. Thus, while it grows in vivo it must acquire haemin (in addition to iron) to satisfy its requirement for this iron-containing compound [26]. However, the uptake of haemin can partially supply the iron required for cell growth [16]. Therefore, this bacterium must have evolved a high-affinity iron uptake system or systems capable of scavenging iron from the host. Furthermore, $H$. influenzae biogroup aegyptius belongs to a family of bacteria that obtain iron by direct interaction with the host chelating proteins transferrin and lactoferrin and do not secrete extracellular siderophore compounds [27-32].

Based on these data and a previous report [5] which indicated that BPF strains constitute a distinct invasive clone of $H$. influenzae, the characterisation of iron acquisition in the prototype strain F3031 was undertaken. The results presented here show that this strain grew even in an iron-chelated culture medium in the absence of human transferrin. Thus, strain F3031 may express a siderophore-independent iron uptake system similar to that encoded by the hitABC genes, recently shown to be essential for iron acquisition by nontypable $H$. influenzae strains [22]. Strain F3031 also had the ability to bind human transferrin. This binding activity in $H$. influenzae is specific for human transferrin $[30,33]$, and the acquisition of iron from this glycoprotein is mediated by two outer-membrane proteins $[9,34]$, a higher mol.wt protein of 94$106 \mathrm{kDa}$, referred to as transferrin-binding protein $\mathrm{A}$ $(\mathrm{TbpA})$, and a lower mol.wt protein of $58-76 \mathrm{kDa}$, referred to as transferrin-binding protein $\mathrm{B}(\mathrm{TbpB})$. Accordingly, transferrin-binding protein homologues were detected in the outer membrane of BPF strain F3031. These homologues displayed the same electrophoretic mobility and showed antigenic similarity with the transferrin-binding proteins of strain Eagan. The transferrin-binding phenotype of BPF strain F3031 may reflect not only the mechanism by which this pathogen acquires iron during the disseminated infections in children, but it may also point to the pathway by which it attaches to and invades the human endothelial cell line used in a tissue culture model $[8,35]$. The ability of the periodontal pathogen
Actinobacillus actinomycetemcomitans to enter human epithelial cells was inhibited by human transferrin [36], suggesting that transferrin and its receptor are involved in this process.

The fact that the BPF isolate grew in sBHI containing EDDHA demonstrated that it expressed an iron acquisition system able to scavenge iron from this synthetic iron chelator. Furthermore, its ability to grow when PPIX was substituted for haemin suggests that the bacterium must acquire iron via a siderophoreindependent iron acquisition system as described in several gram-negative bacteria $[20,22,24,37,38]$. One such system is encoded by the hit $A B C$ operon in nontypable $H$. influenzae strains [22]. The hitA gene codes for an iron-regulated protein, detected as a 40$\mathrm{kDa}$ periplasmic polypeptide in strain Eagan [11], that shows high homology to $s f u A, f b p A, a f u A(\mathrm{Ap})$ and afuA(Aa) of Serratia marcescens [37], N. meningitidis [21], A. pleuropneumoniae [39] and A. actinomycetemcomitans [40], respectively. Utilisation of a polyclonal antiserum against the gonococcal $\mathrm{FbpA}$ protein indicated that strain F3031 had a periplasmic FbpA (or HitA) homologue. The presence of the HitA homologue, in addition to the earlier evidence that the BPF isolate was able to grow when PPIX was substitiuted for haemin, suggests that this strain acquires iron via a mechanism similar to the system encoded by the hitABC genes in non-typable $H$. influenzae [22]. However, the structure of this homologue seems to be unique, as its apparent mol. wt was smaller than that of the HitA protein of strain Eagan. This difference could be due to a different amino-acid composition affecting the electrophoretic mobility or to a shorter open reading frame. These possibilities are currently under investigation.

H. influenzae strain Eagan also contains a $31-\mathrm{kDa}$ iron-regulated periplasmic protein [11] with unknown biological function. When the N-terminal amino acid sequence of this protein was compared with the GenBank database, high homology was found with fimA and $y f e A$ of $S$. parasanguis and $Y$. pestis, respectively. It has been suggested that FimA, a multi-functional membrane protein involved in adhesion, is part of an ATP-binding membrane transport system that transports unknown substrates [41]. YfeA is part of an $\mathrm{ABC}$ transport system, which also includes the $\mathrm{YfeB}, \mathrm{YfeC}$ and $\mathrm{YfeD}$ proteins, that is involved in inorganic iron utilisation and is required for virulence in $Y$. pestis [24]. The presence of a FimA-like protein was demonstrated in the periplasm of strain F3031 with an antiserum against the $31-\mathrm{kDa}$ protein from the periplasm of strain Eagan. Whole-cell lysates of several type $\mathrm{b}$ and non-typable $H$. influenzae strains also contained a FimA-like protein (data not shown). Furthermore, sequence analysis of the $H$. influenzae $\mathrm{Rd}$ genome showed that this strain also contains a fimA locus [23]. These results and observations strongly suggest that the BPF FimA-like 
protein is involved in iron acquisition via a siderophore-independent system and this hypothesis is under investigation.

Iron regulation of gene expression in the BPF clone biogroup aegyptius is an interesting aspect of the biology of this poorly characterised micro-organism. Immunoblot analysis and dot-blot assays showed that the transferrin-binding activity and the expression of tbpB, hitA and fimA-like genes in $H$. influenzae type b strain Eagan were well controlled by the concentration of free iron in the sBHI medium. On the other hand, the regulation of the biosynthesis of $\mathrm{TbpA}$ in this strain was more relaxed, as similar amounts of this protein were detected in the outer membrane of cells grown under either iron-rich or iron-limiting conditions. A similar analysis showed that the synthesis of TbpA and TbpB proteins was poorly regulated in strain F3031 when cells were cultured under comparable iron-replete and iron-limiting conditions. Furthermore, transferrin-binding acitivity was less sensitive to iron than in strain Eagan, and the HitA and FimA homologues were produced almost independently of the iron content of the medium. Another difference is that the hitA homologue encodes a slightly smaller peptide.

The more relaxed iron regulation in the expression of the aforementioned genes in strain F3031 cannot be attributed to the culture conditions, because electrophoretic analysis of cells cultured under the same conditions revealed iron-repressible membrane and periplasmic proteins. A Fur homologue was identified, but its role remains to be elucidated. Nevertheless, genetic complementation of the fur mutant strain RRJCl of $E$. coli [15] with the cloned fur gene of strain F3031 was able to restore iron regulation of gene expression in the fur mutant strain (data not shown). One possible explanation for the defective iron regulation of the $t b p A, t b p B$, hitA and fimA homologues in strain F3031 is the total absence of, or the presence of defective, Fur boxes in the promoter region of these genes. Alternatively, the expression of these genes might be under the control of other regulatory elements expressed only under distinctive growth conditions, such as those found in the infected host. The last possibility is supported by a recent report that novel regulatory mechanisms may be involved in the control of the expression of ironresponsive genes in $H$. influenzae [42].

In conclusion, this study not only gives information on the effect of iron on gene expression and the potential iron-uptake mechanisms of the BPF strain, but also demonstrates that the genes encoding some of the iron-uptake homologues of this strain possess unique regulatory and structural features. These particular features may also support the findings of Musser and Selander [5] which showed the genetic diversity of the biogroup aegyptius and demonstrated that the BPF clone represents a distinct bacterial lineage within the Haemophilus genus.

This work was supported by NIH grants AI37781 to L.A.A. and AI19018 to J.H.C. We are grateful to Drs D. J. Brenner, S. H. Goodgal, S. Morse and S. A. M. Loosmore for providing the BPF isolate, the $H$. influenzae Eagan strain, the anti-FbpA serum and the anti-rTbp antisera, respectively.

\section{References}

1. Brazilian Purpuric Fever Study Group. Brazilian purpuric fever: epidemic purpura fulminans associated with antecedent purulent conjunctivitis. Lancet 1987; 2: 757-761.

2. Brazilian Purpuric Fever Study Group. Haemophilus aegyptius bacteraemia in Brazilian purpuric fever. Lancet 1987; 2: $761-763$.

3. Centers for Disease Control. Brazilian purpuric fever: Haemophilus aegyptius bacteremia complicating purulent conjunctivitis. MMWR Morbid Mortal Wkly Rep 1986; 35: 553-554.

4. Brenner DJ, Mayer LW, Carlone GM et al. Biochemical, genetic, and epidemiologic characterization of Haemophilus influenzae biogroup aegyptius (Haemophilus aegyptius) strains associated with Brazilian Purpuric Fever. J Clin Microbiol 1998; 26: 1524-1534.

5. Musser JM, Selander RK. Brazilian purpuric fever: evolutionary genetic relationships of the case clone of Haemophilus influenzae biogroup aegyptius to encapsulated strains of Haemophilus influenzae. J Infect Dis 1990; 161: 130-133.

6. St Geme JW, Gilsdorf JR, Falkow S. Surface structures and adherence properties of diverse strains of Haemophilus influenzae biogroup aegyptius. Infect Immun 1991; 59: 33663371.

7. Rubin LG, Gloster ES, Carlone GM, and the Brazilian Purpuric Fever Study Group. An infant rat model of bacteremia with Brazilian purpuric fever isolates of Haemophilus influenzae biogroup aegyptius. J Infect Dis 1989; 160: 476-482.

8. Quinn FD, Weyant RS, Worley MJ, White EH, Utt EA, Ades EA. Human microvascular endothelial tissue culture cell model for studying pathogenesis of Brazilian purpuric fever. Infect Immun 1995; 63: 2317-2322.

9. Gray-Owen SD, Loosmore S, Schryvers AB. Indentification and characterization of genes encoding the human transferrinbinding proteins from Haemophilus influenzae. Infect Immun 1995; 63: 1201-1210.

10. Actis LA, Potter SA, Crosa JH. Iron-regulated outer membrane protein OM2 of Vibrio anguillarum is encoded by virulence plasmid pJM1. J Bacteriol 1985; 161: 736-742.

11. Harkness RE, Chong $\mathrm{P}$, Klein $\mathrm{MH}$. Identification of two ironrepressed periplasmic proteins in Haemophilus influenzae. $J$ Bacteriol 1992; 174: 2425-2430.

12. Wanner BL. Phosphorus assimilation and control of the phosphate regulon. In: Neidhardt FC, Curtiss R, Ingraham JL et al. (eds) Escherichia coli and Salmonella cellular and molecular biology, 2nd edn, vol 1. Washington, DC, ASM Press. 1996: 1357-1381

13. Bradford MM. A rapid and sensitive method for the quantitation of microgram quantities of protein utilizing the principle of protein-dye binding. Anal Biochem 1976; 72: 248-254.

14. Towbin H, Staehelin T, Gordon J. Electrophoretic transfer of proteins from polyacrylamide gels to nitrocellulose sheets: procedure and some applications. Proc Natl Acad Sci USA 1979; 76: 4350-4354.

15. Tolmasky ME, Wertheimer AM, Actis LA, Crosa JH. Characterization of the Vibrio anguillarum fur gene: role in regulation of expression of the FatA outer membrane protein and catechols. $J$ Bacteriol 1994; 176: 213-220.

16. Holland J, Towner $\mathrm{KJ}$, Williams P. Isolation and characterisation of Haemophilus influenzae type $\mathrm{b}$ mutants defective in transferrin-binding and iron assimilation. FEMS Microbiol Lett 1991; 77: 283-288.

17. Hantke K. Cloning of the repressor protein gene of ironregulated systems in Escherichia coli K12. Mol Gen Genet 1984; 197: 337-341.

18. Loosmore SM, Yang Y, Coleman DC et al. Cloning and 
expression of the Haemophilus influenzae transferrin receptor genes. Mol Microbiol 1996; 19: 575-586.

19. Berish SA, Kapczynski DR, Morse SA. Nucleotide sequence of the Fbp gene from Neisseria meningitidis. Nucleic Acids Res 1990; 18: 4596.

20. Berish SA, Mietzner TA, Mayer LW, Genco CA, Holloway BP, Morse SA. Molecular cloning and characterization of the structural gene for the major iron-regulated protein expressed by Neisseria gonorrhoeae. J Exp Med 1990; 171: 1535-1546.

21. Genco CA, Desai PJ. Iron acquisition in the pathogenic Neisseria. Trends Microbiol 1996; 4: 179-184.

22. Sanders JD, Cope LD, Hansen EJ. Identification of a locus involved in the utilization of iron by Haemophilus influenzae. Infect Immun 1994; 62: 4515-4525.

23. Fleischmann $\mathrm{RD}$, Adams $\mathrm{MD}$, White $\mathrm{O}$ et al. Whole-genome random sequencing and assembly of Haemophilus influenzae Rd. Science 1995; 269: 496-512

24. Bearden SW, Staggs TM, Perry RD. An ABC transporter system of Yersinia pestis allows utilization of chelated iron by Escherichia coli SAB11. J Bacteriol 1998; 180: 1135-1147.

25. White DC, Granick S. Heme biosynthesis in Haemophilus. $J$ Bacteriol 1963; 85: 842-850.

26. Coulton JW, Pang JCS. Transport of heme by Haemophilus influenzae type b. Curr Microbiol 1983; 9: 93-98.

27. Crosa JH. Genetics and molecular biology of siderophoremediated iron transport in bacteria. Microbiol Rev 1989; 53 517-530.

28. Gray-Owen SD, Schryvers AB. Bacterial transferrin and lactoferrin receptors. Trends Microbiol 1996; 4: 185-191.

29. Herrington DA, Sparling PF. Haemophilus influenzae can use human transferrin as a sole source for required iron. Infect Immun 1985; 48: 248-251.

30. Morton DJ, Williams P. Utilization of transferrin-bound iron by Haemophilus species of human and porcine origins. FEMS Microbiol Lett 1989; 65 123-128.

31. Morton DJ, Williams P. Siderophore-independent acquisition of transferrin-bound iron by Haemophilus influenzae type b.
$J$ Gen Microbiol 1990; 136: 927-933.

32. Otto BR, Verweij-van Vught AMJJ, MacLaren DM. Transferrins and heme-compounds as iron sources for pathogenic bacteria. Crit Rev Microbiol 1992; 18: 217-233.

33. Schryvers AB. Characterization of the human transferrin and lactoferrin receptors in Haemophilus influenzae. Mol Microbiol 1988; 2: 467-472.

34. Schryvers AB. Identification of the transferrin- and lactoferrinbinding proteins in Haemophilus influenzae. $J$ Med Microbiol 1989; 29: $121-130$.

35. Weyant RS, Quinn FD, Utt EA et al. Human microvascular endothelial cell toxicity caused by Brazilian purpuric feverassociated strains of Haemophilus influenzae biogroup aegyptius. J Infect Dis 1994; 169: 430-433.

36. Meyer DH, Fives-Taylor PM. The role of Actinobacillus actinomycetemcomitans in the pathogenesis of periodontal disease. Trends Microbiol 1997; 5: 224-228.

37. Angerer A, Gaisser S, Braun V. Nucleotide sequences of the $s f u A, s f u B$, and $s f u C$ genes of Serratia marcescens suggest a periplasmic-binding-protein-dependent iron transport mechanism. $J$ Bacteriol 1990; 172: 572-578.

38. Angerer A, Klupp B, Braun V. Iron transport systems of Serratia marcescens. J Bacteriol 1992; 174: 1378-1387.

39. Chin N, Frey J, Chang C-F, Chang Y-F. Identification of a locus involved in the utilization of iron by Actinobacillus pleuropneumoniae. FEMS Microbiol Lett 1996; 143: 1-6.

40. Willemsen PTJ, Vulto I, Boxem M, De Graaff J. Characterization of a periplasmic protein involved in iron utilization of Actinobacillus actinomycetemcomitans. J Bacteriol 1997; 179: 4949-4952.

41. Fenno JC, Shaikh A, Spatafora G, Fives-Taylor P. The fimA locus of Streptococcus parasanguis encodes an ATP-binding transport system. Mol Microbiol 1995; 15: 849-863.

42. Morton DJ, Musser JM, Stull TL. Expression of the Haemophilus influenzae transferrin receptor is repressible by hemin but not elemental iron alone. Infect Immun 1993; 61: 4033-4037. 